Article

\title{
Fluorescence-Based Detection of Benzene, Toluene, Ethylbenzene, Xylene, and Cumene (BTEXC) Compounds in Fuel-Contaminated Snow Environments
}

\author{
Dana J. DiScenza, Lauren E. Intravaia, Anna Healy, Sage B. Dubrawski and Mindy Levine *(D) \\ Department of Chemistry, University of Rhode Island, Kingston, RI 02881, USA; \\ ddiscenza92@gmail.com (D.J.D.); lintravaia@my.uri.edu (L.E.I.); shealy0257@gmail.com (A.H.); \\ sage_dubrawski@my.uri.edu (S.B.D.) \\ * Correspondence: mindy.levine@gmail.com or mlevine@chm.uri.edu; Tel.: +1-401-874-4243
}

Received: 5 December 2018; Accepted: 10 January 2019; Published: 15 January 2019

\begin{abstract}
Reported herein is the sensitive and selective cyclodextrin-promoted fluorescence detection of benzene, toluene, ethylbenzene, xylene, and cumene (BTEXC) fuel components in contaminated snow samples collected from several locations in the state of Rhode Island. This detection method uses cyclodextrin as a supramolecular scaffold to promote analyte-specific, proximity-induced fluorescence modulation of a high-quantum-yield fluorophore, which leads to unique fluorescence responses for each cyclodextrin-analyte-fluorophore combination investigated and enables unique pattern identifiers for each analyte using linear discriminant analysis (LDA). This detection method operates with high levels of sensitivity (sub-micromolar detection limits), selectivity ( $100 \%$ differentiation between structurally similar compounds, such as ortho-, meta-, and para-xylene isomers), and broad applicability (for different snow samples with varying chemical composition, $\mathrm{pH}$, and electrical conductivity). The high selectivity, sensitivity, and broad applicability of this method indicate significant potential in the development of practical detection devices for aromatic toxicants in complex environments.
\end{abstract}

Keywords: snow; BTEXC; cyclodextrin; fluorescence spectroscopy

\section{Introduction}

The ubiquitous prevalence of benzene, toluene, ethylbenzene, xylenes, and cumene (BTEXC) in the environment [1] is a result of the fact that they are components of various fuel types, including gasoline [2] and crude oil [3]. The deleterious health effects associated with exposure to these compounds varies somewhat by compound [4], with benzene in particular demonstrated to have high toxicity [5] and carcinogenicity [6]. Even relatively less toxic analytes, such as toluene, have still been reported to have negative health effects for humans [7] and animals [8]. Literature-reported detection methods for BTEXC compounds include gas chromatography-mass spectrometry (GC-MS) [9], liquid chromatography-mass spectrometry (LC-MS) [10], and electrochemical methods [11]. Although many of the mass spectral-based methods provide extraordinarily high levels of sensitivity and selectivity, they are often not suitable for use in real-world environments due to the bulky and costly instrumentation required, nor are they suitable for rapid screening of large numbers of potentially contaminated samples, due to the time required for analysis of each sample. While the electrochemical methods can be portable [12], rapid [13], and highly sensitive [14], the general applicability of such methods has not yet been determined. 
The use of fluorescence-based methods for toxicant detection can avoid many of the practical challenges associated with mass spectral detection [15]. In particular, fluorescence-based detection in complex environments can occur using a hand-held device while maintaining high sensitivity [16], and can also be performed rapidly to enable high-throughput sample screening [17]. Fluorescence-based detection methods have been reported for a broad variety of analytes using a range of fluorescent sensors, including explosive detection via fluorescent conjugated polymers [18] and nanoparticles [19], anion detection via supramolecular fluorescent sensors [20], and cation detection via interactions of cationic analytes with small-molecule, high-quantum-yield fluorophores [21]. The use of fluorescence-based methods for BTEXC detection in real-world environments has been reported only rarely to date, in combination with capillary electrophoresis [22] or other chromatographic methods to enable separation prior to detection [23].

Our research group has reported a fundamentally new method for fluorescence-based toxicant detection, using cyclodextrin as a supramolecular scaffold to promote proximity-induced energy transfer from a toxicant to a high-quantum-yield fluorophore acceptor in cases where the toxicant is photophysically active [24], and proximity-induced analyte-specific fluorescence modulation in cases where the toxicant is not photophysically active (Figure 1) [25].
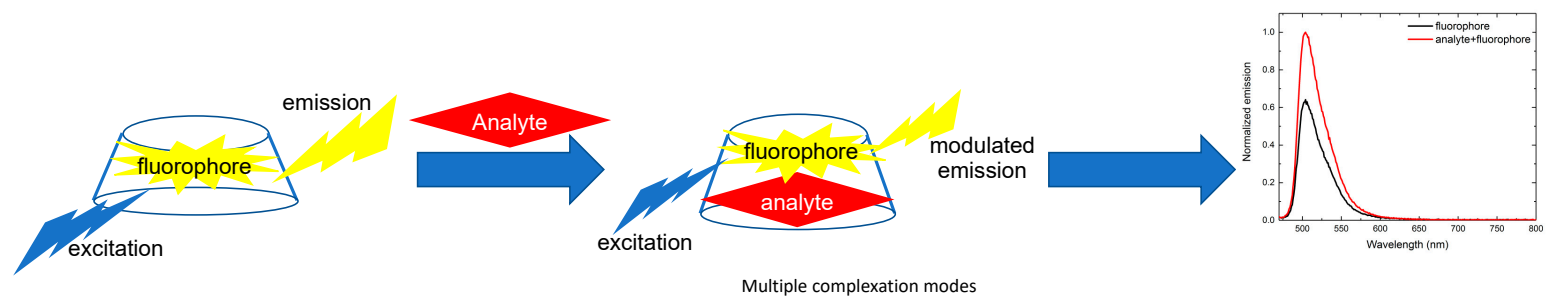

Figure 1. Scheme of cyclodextrin-promoted fluorescence modulation. This figure shows one possible complexation mode in which both the fluorophore and analyte are bound in the cyclodextrin. Other complexation modes are possible.

We have demonstrated that this system enables effective detection in the complex environments of human plasma [26], urine [27], and breast milk [28], as well as in aqueous extracts collected from crude oil samples [29], in contaminated marine environments [30], and in extracts from a large-scale fuel spill event [31].

One potential source of BTEXC exposure is through snow melt, a particular concern in geographic regions in which snowfall is prevalent, including in New England [32]. Literature reports indicate that BTEXC is often found in snow [33], and that snow melting leads to BTEXC contamination of the local water supply [34], which affects species who consume the water as well as those who live in the water [35]. Reported herein is the application of our cyclodextrin-promoted system for BTEXC detection in snow melt, collected from several geographic regions throughout the state of Rhode Island, and the ability of the cyclodextrin-based system to accomplish sensitive, selective, and rapid detection of these ubiquitous environmental pollutants. Preliminary efforts towards the development of quantitative detection systems are also discussed.

\section{Materials and Methods}

\subsection{Instruments and Reagents}

All toxicant analytes, control analytes, and fluorophores (compounds 1-9, Figure 2) were purchased from Millipore-Sigma chemical company and used as received, unless otherwise noted. All cyclodextrins were purchased from Tokyo Chemical Industry (TCI) and used as received. Fluorescence spectra were obtained using a Shimadzu RF6000 spectrophotofluorimeter with $3.0 \mathrm{~nm}$ excitation and emission slit widths. All gas chromatography - mass spectrometry (GC-MS) measurements were obtained using a Shimadzu GC-MS QP2020 gas chromatograph-mass spectrometer (obtained from 
Shimadzu Scientific Instruments, Marlborough, MA, USA). All pH measurements were obtained using a Microlab FS-522 instrument. Conductivity experiments were performed using a Thermo Scientific Orion 3-Star Benchtop Conductivity Kit.<smiles>c1ccccc1</smiles>

1 benzene<smiles>Cc1ccccc1</smiles>

2 toluene<smiles>CCc1ccccc1</smiles>

3 ethylbenzene<smiles>Cc1ccccc1C</smiles>

4 o-xylene<smiles>Cc1cccc(C)c1</smiles>

5<smiles>Cc1ccc(C)cc1</smiles>

6 p-xylene<smiles>CC(C)c1ccccc1</smiles>

7 cumene<smiles>C1CCOC1</smiles>

8 tetrahydrofuran

Figure 2. Structures of analytes 1-7, control analyte 8, and fluorophore 9.

\subsection{Sample Collection Procedures}

Snow samples were collected from three locations around Rhode Island: Newport, Providence, and Kingston (Figure 3), 24 hours after a snowfall event. Samples were stored in amber high-density polyethylene bottles obtained from Fisher Scientific chemical company, which were transported to the University of Rhode Island in a climate-controlled vehicle within one hour of collection and stored in the laboratory refrigerator until used for analysis.

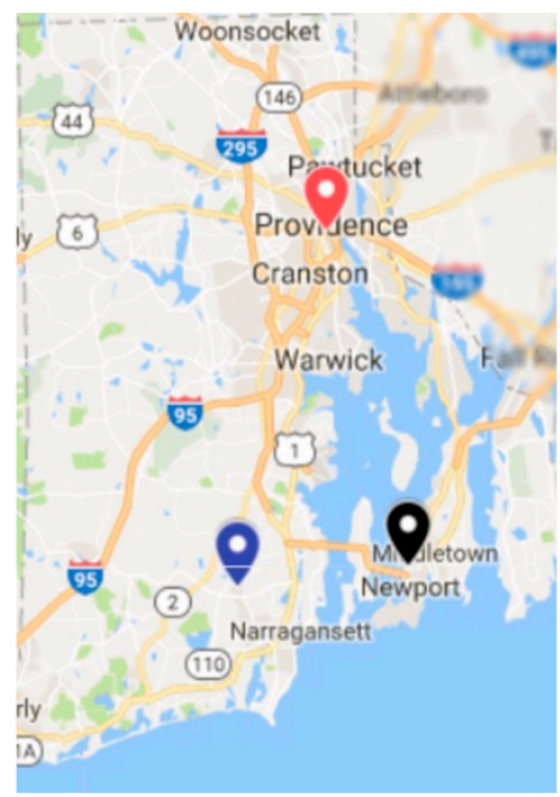

Figure 3. Map of snow sampling locations. The black marker represents Newport snow, the red marker represents Providence snow, and the blue marker represents Kingston snow. The map has been digitally manipulated so that only the state of Rhode Island is in focus. 


\subsection{Details for Snow Characterization Experiments}

\subsubsection{GC-MS Experiments}

Approximately $10 \mathrm{~mL}$ of melted snow and $10 \mathrm{~mL}$ of dichloromethane were added to a separatory funnel. The separatory funnel was shaken vigorously, and the aqueous layer was discarded. Another $10 \mathrm{~mL}$ of melted snow was added to the organic layer, and the extraction procedure was repeated. The organic layer was dried with $\mathrm{MgSO}_{4}$, concentrated using a rotary evaporator, filtered, and analyzed using GC-MS.

All GC-MS measurements were obtained on a Shimadzu QP2020 gas chromatograph-mass spectrometer with the following settings: column: Shimadzu SH-Rxi-5Sil MS (30 m $\times 0.25 \mathrm{~mm} \times$ $0.25 \mu \mathrm{m}$ ); oven temperature: $45^{\circ} \mathrm{C}$, hold for $3 \mathrm{~min}, 8{ }^{\circ} \mathrm{C} / \mathrm{min}$ to $220^{\circ} \mathrm{C}$, hold for $15 \mathrm{~min}$; injection temperature: $200{ }^{\circ} \mathrm{C}$; splitting ratio: splitless; MS ion source temperature: $230^{\circ} \mathrm{C}$; interface temperature: $150^{\circ} \mathrm{C}$; solvent cut time: $3.5 \mathrm{~min}$.

\subsection{2. $\mathrm{pH}$ Experiments}

All $\mathrm{pH}$ experiments were performed using a MicroLab FS-522 instrument (obtained from MicroLab, Inc, in Bozeman, MT). The $\mathrm{pH}$ probe was calibrated using Fisherbrand $\mathrm{pH} \mathrm{4,} \mathrm{7,} \mathrm{and}$ 10 pre-made buffer solutions, obtained from Fisher Scientific Chemical Company. $\mathrm{pH}$ values were obtained using MicroLab software version 6.3.4.

\subsubsection{Conductivity Experiments}

All conductivity experiments were performed using a Thermo Scientific Orion 3-Star Benchtop Conductivity Kit. The conductivity probe was rinsed thoroughly with deionized water between samples.

\subsection{Details for Fluorescence Modulation Experiments}

In a quartz cuvette, $1.25 \mathrm{~mL}$ of a $10 \mathrm{mM}$ cyclodextrin solution dissolved in phosphate buffered saline (PBS) and $1.25 \mathrm{~mL}$ of a melted snow sample were combined and mixed thoroughly by shaking. For control experiments in the absence of snow, $1.25 \mathrm{~mL}$ of a $10 \mathrm{mM}$ cyclodextrin solution in PBS and $1.25 \mathrm{~mL}$ deionized (DI) water were combined and mixed thoroughly. Next, $100 \mu \mathrm{L}$ of a $0.1 \mathrm{mg} / \mathrm{mL}$ fluorophore 9 solution in tetrahydrofuran (THF) was added, and the fluorescence emission spectrum was taken four times using a $460 \mathrm{~nm}$ excitation wavelength to excite the fluorophore. Then, $20 \mu \mathrm{L}$ of analytes $1-8(1.0 \mathrm{mg} / \mathrm{mL}$ in THF) were added to the mixture, and the resulting solution was again excited four times at $460 \mathrm{~nm}$. The fluorescence emission spectra were integrated vs. wavenumber on the $\mathrm{X}$-axis using OriginPro software, and the degree of fluorescence modulation was determined by the ratio of the integrated emission of the fluorophore in the presence of analyte to the integrated emission of the fluorophore in the absence of analyte, as shown in Equation (1):

$$
\text { Fluorescence modulation }=F l_{\text {analyte }} / F l_{\text {blank }}
$$

where $F l_{\text {analyte }}$ is the integrated emission of the fluorophore in the presence of the analyte, and $F l_{\text {blank }}$ is the integrated emission of the fluorophore in the absence of the analyte. Fluorescence modulation ratios greater than 1 indicate an enhancement of fluorescence emission of the fluorophore in the presence of the analyte, fluorescence modulation ratios less than 1 indicate a decrease in fluorescence emission of the fluorophore in the presence of the analyte, and fluorescence modulation ratios close to 1 indicate minimal change in the fluorescence emission of the fluorophore in the presence of the analyte.

\subsection{Details for Array Generation Experiments}

Arrays were generated using SYSTAT 13 statistical computing software with the following settings: (a) Classical discriminant analysis; (b) Grouping variable: analytes; (c) Predictors: cyclodextrins; and (d) Long-range statistics: Mahal. 


\subsection{Details for Limit-of-Detection Experiments}

Limit-of-detection experiments were conducted following literature-reported procedures [36]. In brief, $1.25 \mathrm{~mL}$ of a $10 \mathrm{mM}$ methyl- $\beta$-cyclodextrin solution and $1.25 \mathrm{~mL}$ of a snow sample were added to a quartz cuvette and mixed thoroughly. $100 \mu \mathrm{L}$ of fluorophore 9 was added to the cuvette, and the solution was excited six times at $460 \mathrm{~nm}$.

Next, $5 \mu \mathrm{L}$ of analyte was added, and again the solution was excited six times at $460 \mathrm{~nm}$. This step was repeated for $10 \mu \mathrm{L}$ of analyte, $15 \mu \mathrm{L}$ of analyte, $20 \mu \mathrm{L}$ of analyte, $25 \mu \mathrm{L}$ of analyte, and $30 \mu \mathrm{L}$ of analyte.

All fluorescence emission spectra were integrated vs. wavenumber on the $\mathrm{X}$-axis, and calibration curves were generated. The curves plotted the analyte concentration, measured in $\mu \mathrm{M}$, on the $\mathrm{X}$-axis and the fluorescence modulation ratio on the Y-axis. The curve was fitted to a straight line, and the equation of the line was determined. The limit of detection (LOD) was calculated according to Equation (2):

$$
\text { Limit of Detection }(\mathrm{LOD})=3\left(S D_{\text {blank }}\right) / \mathrm{m}
$$

where $S D_{\text {blank }}$ is the standard deviation of the blank sample and $m$ is the slope of the calibration curve. In all cases, the LOD was calculated as a concentration in $\mu \mathrm{M}$.

\section{Results}

\subsection{Component Selection Details}

\subsubsection{Sampling Location Selection}

For this research, we chose areas of Rhode Island that are known to be highly populated-meaning that large populations have potential toxicant exposure-as well as areas that had a lot of traffic, meaning that high concentrations of fuel are used in a relatively small area. Newport snow was obtained from a parking lot of a shopping complex that is frequented by passenger cars, delivery trucks, and buses. Providence snow was collected from a busy street with cars, buses, and waste management vehicles [37]. The samples collected from Providence were of particular interest, as Providence has already been reported as a highly polluted city with significant quantities of acid rain, and the possibility for acidic snow exists as well [38]. Kingston snow was collected from a highly frequented street at the University of Rhode Island, with a lot of cars, buses, and construction vehicles.

\subsubsection{Cyclodextrin Selection}

Previous work in our group has used a variety of commercially available cyclodextrin hosts, including $\alpha$-cyclodextrin, comprised of 6 glucose units; $\beta$-cyclodextrin, containing 7 glucose units; and $\gamma$-cyclodextrin, comprised of 8 glucose units; as well as two $\beta$-cyclodextrin derivatives: methyl- $\beta$-cyclodextrin, with an average of 1.8 methyl groups per glucose unit [39], and 2-hydroxypropyl- $\beta$-cyclodextrin, with an average of 0.65 hydroxypropyl groups per glucose unit [39]. For these experiments, we selected $\beta$-cyclodextrin, methyl- $\beta$-cyclodextrin, and 2-hydroxypropyl- $\beta$-cyclodextrin as supramolecular hosts, based on the previously demonstrated high performance of $\beta$-cyclodextrin-derived hosts in promoting highly analyte-specific, proximity-induced interactions, Ref. [31] and as a result of the fact that $\beta$-cyclodextrin is a known host for single-ring aromatic guests.

\subsubsection{Fluorophore Selection}

For these experiments, a commercially available, methyl-substituted boron-dipyrromethene (BODIPY) derivative was used, based on the well-documented ability of BODIPY fluorophores to display high quantum yields and robust performance under a variety of experimental conditions [40-42]. 


\subsubsection{Analyte Selection}

Analytes 1-7 were selected due to their known prevalence in automobile fuel, as well as their known and suspected toxicities. Analyte 8 was chosen due to its ability to dissolve analytes 1-7, and its miscibility with the melted snow samples, and was used as a control analyte to elucidate any effects of the solvent on the observed fluorescence modulation ratios.

\subsection{Undoped Snow Sample Experiments}

\subsubsection{GC-MS Experiments on Undoped Snow Samples}

Gas chromatography - mass spectrometry (GC-MS) was used to characterize the undoped (i.e., analyte-free) snow melt samples (Figure 4), with all samples showing peaks in the chromatograms corresponding to long-chain alkanes [43] and amides [44] that are typically found in fuel and other environmental contamination sources. Snow melt from Newport showed the lowest number of peaks, corresponding to the fewest organic contaminants, likely due to the sampling location selected (Newport sample from parking lot; Providence and Kingston samples from street). Melted snow from Providence showed the highest amount of fuel components, likely due to the known pollution and traffic density in this urban area. Melted snow from Kingston showed a peak from triacetin, which was not found in the other two samples. It is also commonly used as a diesel fuel stabilizer [45], which is likely due to the large number of construction vehicles in the local geographic area. All of the samples showed a peak for 9-octadecenamide, a common surfactant that is added to fuel [46].

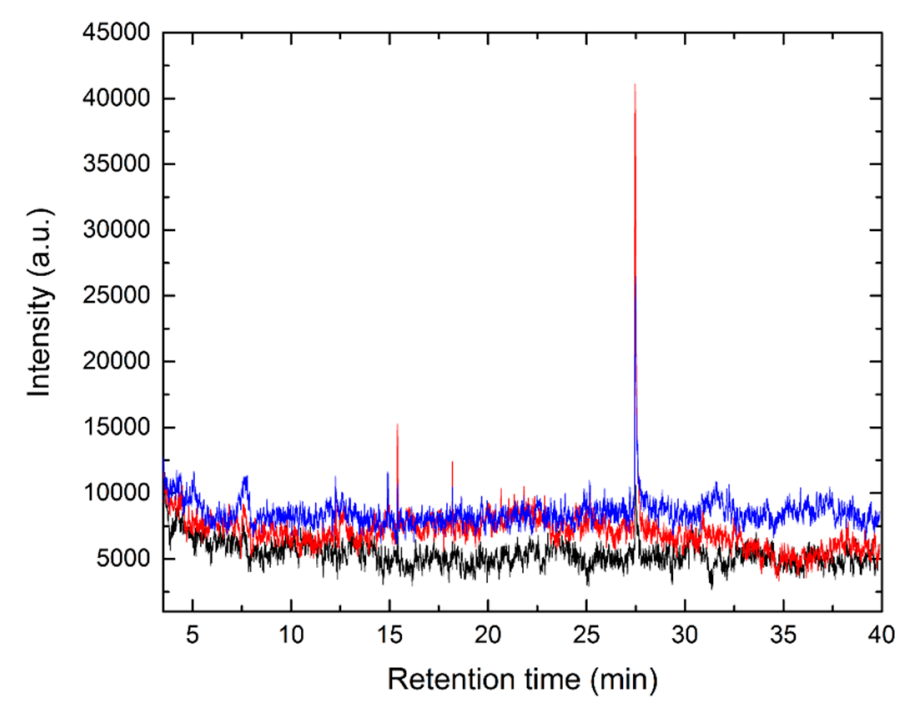

Figure 4. Gas chromatography - mass spectrometry (GC-MS) overlay of snow samples, where the black line represents Newport snow, the red line represents Providence snow, and the blue line represents Kingston snow.

Although there were no peaks corresponding to the BTEXC analytes in the GC-MS spectra for each snow sample, peaks corresponding to other components of automobile fuel strongly suggest the presence of fuel contamination (see Table S2 in Supporting Information for more details). Our inability to detect BTEXC compounds in these samples could be due to their higher volatility compared to the other fuel components detected, as well as the fact that these components volatilized prior to analysis [47].

\subsection{2. $\mathrm{pH}$ and Conductivity Experiments on Undoped Snow Samples}

The $\mathrm{pH}$ and conductivity of the melted snow samples were measured to quantify compositional differences between the samples (Table 1). 
Of note, Providence snow had the lowest $\mathrm{pH}$ of the three snow-melt samples, followed by Kingston and Newport, likely as a result of the greater prevalence of acid rain and acid snow in Providence due to significant urban pollution. The conductivity of each snow melt sample was measured as an indicator of the overall salinity and total electrolyte concentration [48]. Newport had the highest conductivity, followed by Kingston and Providence. This could be due to salting of the roads after snow storms in the parking lot where Newport snow was collected, as well as the street at the University of Rhode Island where Kingston snow was collected. Snow treatments in Providence, by contrast, rely less on salting roadways and more on other options, such as sanding.

Table 1. $\mathrm{pH}$ and conductivity data for sampling locations.

\begin{tabular}{ccc}
\hline Sampling Location & $\mathrm{pH}^{a}$ & ${\text { Conductivity }(\mu \mathrm{s} / \mathrm{cm})^{b}}^{b}$ \\
\hline Newport & 6.48 & 713 \\
Providence & 6.08 & 101 \\
Kingston & 6.46 & 584
\end{tabular}

${ }^{a} \mathrm{pH}$ values were obtained using a MicroLab FS-522 instrument with a $\mathrm{pH}$ probe calibrated using Fisherbrand $\mathrm{pH} 4$, 7 , and 10 buffer solutions. ${ }^{b}$ Conductivity values were obtained using a Thermo Scientific Orion 3-Star Benchtop Conductivity Kit.

\subsubsection{Fluorescence Experiments on Undoped Snow Samples}

Spectroscopic measurements of the emission of fluorophore 9 in undoped (i.e., analyte-free) melted snow further confirmed compositional differences between the samples (Figure 5), as a result of the fact that the fluorophore emission is known to be highly sensitive to environmental differences.

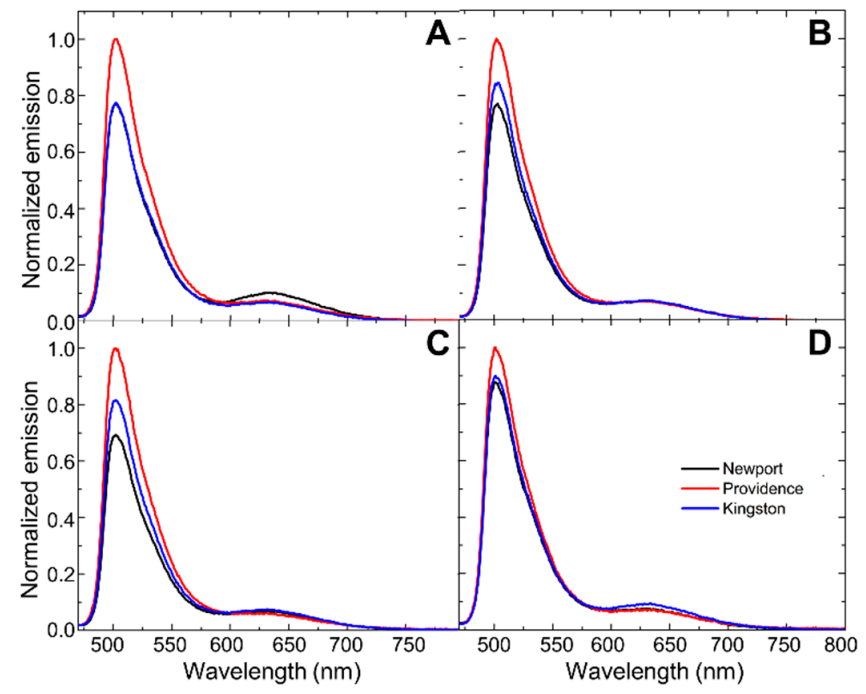

Figure 5. Comparison of the fluorescence response of undoped snow samples with fluorophore $9\left(\lambda_{\mathrm{ex}}=460 \mathrm{~nm}\right)$ with (A) $\beta$-cyclodextrin; (B) methyl- $\beta$-cyclodextrin; (C) 2-hydroxypropyl- $\beta$ cyclodextrin; and (D) phosphate-buffered saline. The black line represents Newport snow, the red line represents Providence snow, and the blue line represents Kingston snow.

Of all the combinations of cyclodextrins and snow samples investigated, fluorophore 9 showed the highest emission intensity in melted snow obtained from Providence. This is likely due to the presence of a large number of fuel components inherently present in the solution which interact favourably with the fluorophore 9-cyclodextrin host-guest complexes to create localized, non-polar areas, resulting in higher quantum yields. Differences between sampling locations were more pronounced with methyl- $\beta$-cyclodextrin and 2-hydroxypropyl- $\beta$-cyclodextrin as hosts, which are both more soluble and more hydrophobic than the unsubstituted $\beta$-cyclodextrin [49]. Although benzene-derived aromatic compounds form strong host-guest complexes with all $\beta$-cyclodextrin 
derived compounds investigated herein, including $\beta$-cyclodextrin [50], methyl- $\beta$-cyclodextrin [51], and 2-hydroxypropyl- $\beta$-cyclodextrin [52], the enhanced solubility, combined with the greater hydrophobic character of methyl- $\beta$-cyclodextrin, promote the stronger complexation of the aromatic guests [53]. This, in turn, results in more sensitive changes in the fluorophore emission signal upon introduction of the BTEXC guests and competitive displacement of the fluorophore from the cyclodextrin cavity.

Array-based analysis was also used to differentiate between integrated fluorescence emission of undoped (i.e., analyte-free) snow samples (Figure 6). In every case, results indicated $100 \%$ success in differentiating between melted snow samples, as a result of the known sensitivity of boron-dipyrromethene (BODIPY) dyes to sample-specific environmental differences, such as organic components (as measured by GC-MS) [54], $\mathrm{pH}$ (which is affected by the presence of acid rain) [55], and salt content (as measured through conductivity) [56], which results in different fluorescence responses and excellent separation between the undoped sample signals.

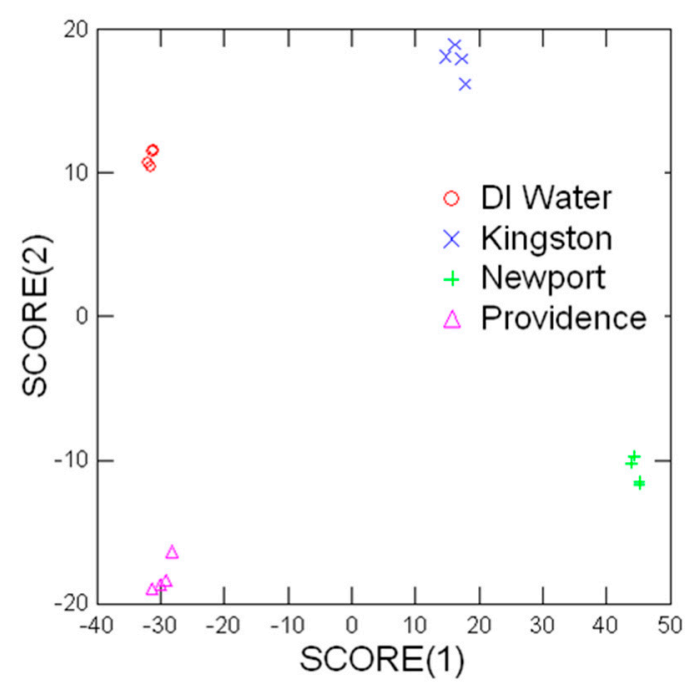

Figure 6. Array response patterns using linear discriminant analysis of fluorescence response signals of fluorophore 9 in undoped snow melt samples, with cyclodextrins as predictors.

\subsection{Analyte-Doped Snow Samples}

\subsubsection{Fluorescence Modulation of Analyte-Doped Snow Samples}

Each cyclodextrin, in combination with fluorophore $\mathbf{9}$ as a signal-transducing element, was used for the detection of specific fuel components within the complex matrices of three real-world snow samples. Micromolar concentrations of analytes 1-7 or control analyte 8 were added to each solution, and the resulting changes in the fluorescence emission of fluorophore 9 in the presence and absence of analyte were calculated using Equation 1 . In every case, the fluorescence modulation values were greater than 1, indicating an enhancement in the fluorescence emission of fluorophore 9 upon introduction of analytes (see Tables S3-S5 in the Electronic Supporting Information (ESI) for more details). The conductivity differences between the snow samples (Newport $>$ Kingston $>$ Providence) led to variable differences in the degree of fluorescence modulation. We discovered in our previous work that higher conductivity, corresponding to a greater salt concentration, influences inclusion complexation [57]. Generally, the fluorescence modulation values were higher in the Newport snow samples, likely due to an increase of favourable hydrophobic interactions. The fluorescence emission of fluorophore 9 in the presence of cyclodextrin hosts is greatest in the presence of methyl- $\beta$-cyclodextrin, followed by 2 -hydroxypropyl- $\beta$-cyclodextrin, $\beta$-cyclodextrin, and phosphate-buffered saline. This is due to the ability of the cyclodextrin hosts to tightly bind fluorophore $\mathbf{9}$ in the cavity via hydrogen-bonding interactions, which decreases the accessibility of non-radiative decay pathways. The fluorescence modulation ratios in the presence of cyclodextrin increased only slightly due to 
attenuated interactions between the fluorophore and analyte, as noted by the low binding-constant values (Table 2) [58,59]. These slight increases can be attributed to the competitive binding with long-chain alkanes. For comparison, the binding constant of heptanol is an order of magnitude higher than for BTEXC compounds in $\beta$-cyclodextrin, although pure hydrocarbon alkanes are expected to have decreased affinities, more directly in line with the BTEXC compounds. Fluorescence modulation ratios are greater in the absence of cyclodextrin due to the greater opportunity for hydrogen bonding and $\pi$-stacking interactions between the aromatic analytes and fluorophores, leading to a greater enhancement in fluorophore emission. While the fluorescence modulation ratios are higher in the absence of cyclodextrin, it is important to note that fluorescence emission was generally higher in the presence of cyclodextrin compared to in the absence of cyclodextrin, as we have seen in our previous work [60]. These results demonstrate that the fluorescence emission was influenced by the sample matrix and cyclodextrin identity, which in turn affects the interactions of the fluorophore with the aromatic analytes investigated (Figure 7).

Table 2. Literature-reported binding constants of analytes 1-7 with $\beta$-cyclodextrin ${ }^{a}$.

\begin{tabular}{cc}
\hline Compound & Binding Constant $\left(\mathbf{M}^{-\mathbf{1}} \mathbf{)}\right.$ \\
\hline $\mathbf{1}$ & 121 \\
$\mathbf{2}$ & 287 \\
$\mathbf{3}$ & 435 \\
$\mathbf{4}$ & 305 \\
$\mathbf{5}$ & 210 \\
$\mathbf{6}$ & 353 \\
$\mathbf{7}$ & $b$ \\
Heptanol & $1000[61]$
\end{tabular}

${ }^{a}$ Binding constant values obtained from Kfoury, 2018. ${ }^{b}$ No binding constant value obtained.

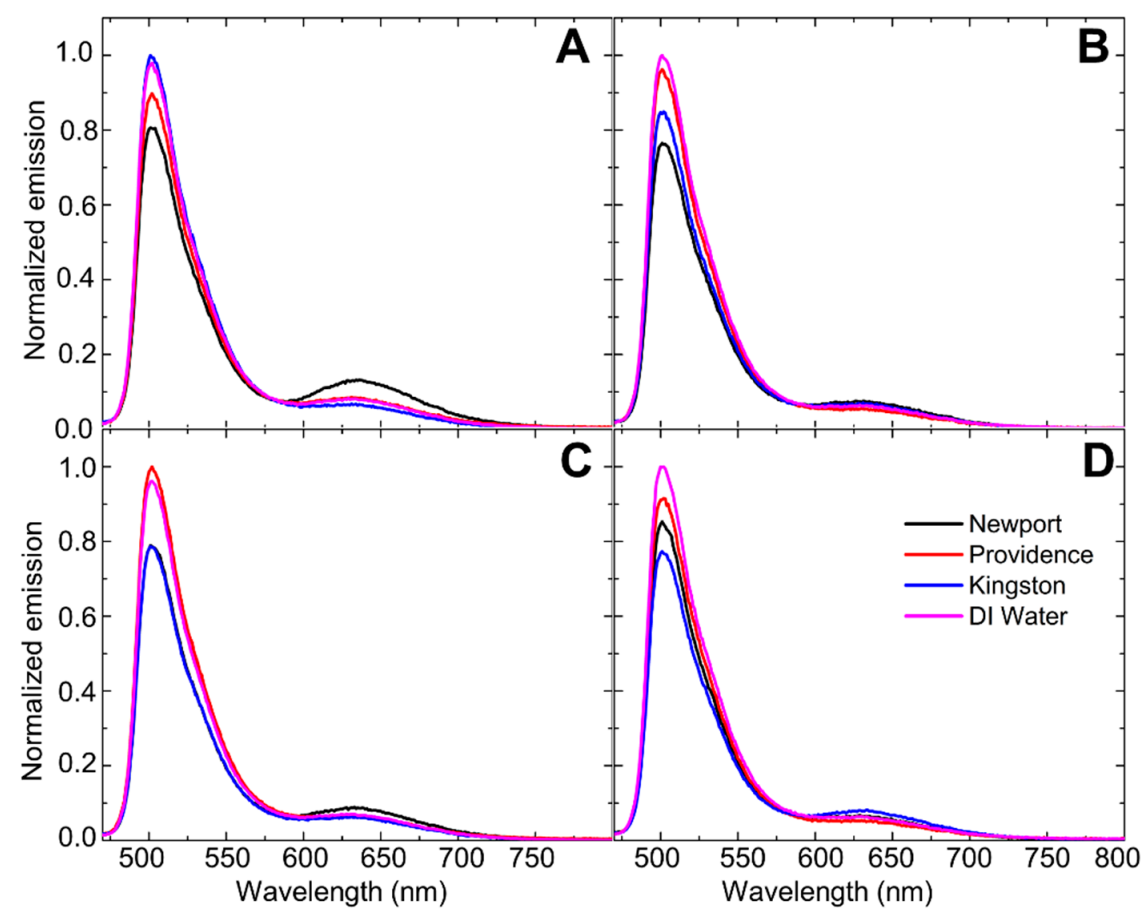

Figure 7. Fluorescence changes of fluorophore $9\left(\lambda_{\mathrm{ex}}=460 \mathrm{~nm}\right)$ with $(\mathrm{A})$ analyte $\mathbf{1}$ with $\beta$-cyclodextrin; (B) analyte $\mathbf{1}$ with phosphate-buffered saline; (C) analyte $\mathbf{8}$ with $\beta$-cyclodextrin; and (D) analyte $\mathbf{8}$ with phosphate-buffered saline in the different sampling locations. The black line represents Newport snow, the red line represents Providence snow, the blue line represents Kingston snow, and the purple line represents deionized water. 


\subsubsection{Array-Based Analysis of Analyte-Doped Snow Samples}

In addition to determining differences in the composition of the snow samples through measuring differences in the fluorescence response patterns, the ability to detect analytes selectively within these complex mixtures is expected to provide significant practical benefits. To that end, the selectivity of the system was determined using array-based analysis of the fluorescence responses of analyte 9 under the different experimental conditions. Linear discriminant analysis of the integrated fluorescence emission of fluorophore 9 using $\beta$-cyclodextrin, methyl- $\beta$-cyclodextrin, and 2-hydroxypropyl- $\beta$-cyclodextrin as predictors, led to $100 \%$ differentiation between analytes $\mathbf{1 - 8}$, which had significant structural similarity in every snow sample targeted (Figure 8).

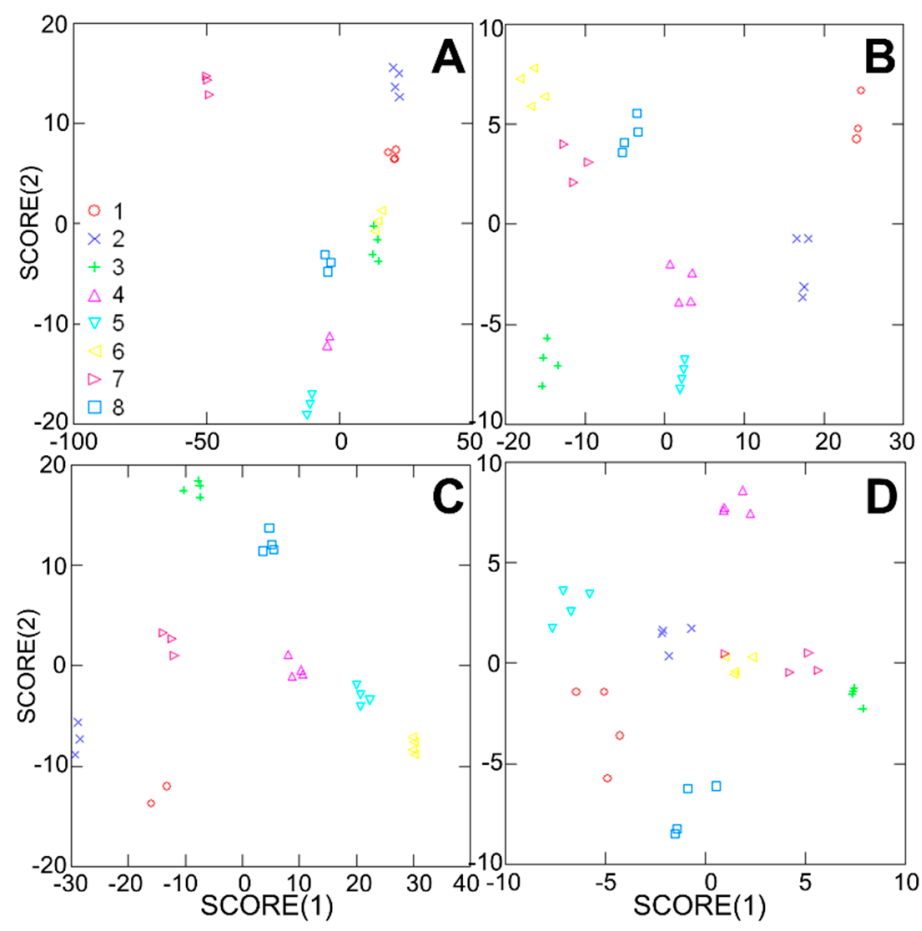

Figure 8. Linear discriminant analysis of fluorescence responses of analytes 1-8 with fluorophore 9 in (A) Newport snow; (B) Providence snow; (C) Kingston snow; and (D) deionized water, using cyclodextrins as predictors.

When the same linear discriminant analysis procedure was repeated using two predictors rather than three, the selectivity of the system decreased, albeit relatively modestly (Figure 9), with the decrease dependent on the identity of the two predictors that remained. When the two predictors were two different cyclodextrin hosts ( $\beta$-cyclodextrin and methyl- $\beta$-cyclodextrin), the ability of the system to differentiate between structurally similar analytes decreased from $100 \%$ to $97 \%$ (Figure $8 \mathrm{C}$ vs. Figure 9A). When the two predictors were $\beta$-cyclodextrin and PBS, the ability of the system to differentiate between structurally similar analytes decreased to $91 \%$. These results indicate that three predictors provide maximum separation, but two predictors can also lead to reasonable separation between structurally similar analytes. The lower selectivity observed when one of the two predictors was PBS compared to the selectivity observed with two cyclodextrin hosts indicates that cyclodextrin hosts are better than PBS at enabling that selectivity to occur. 


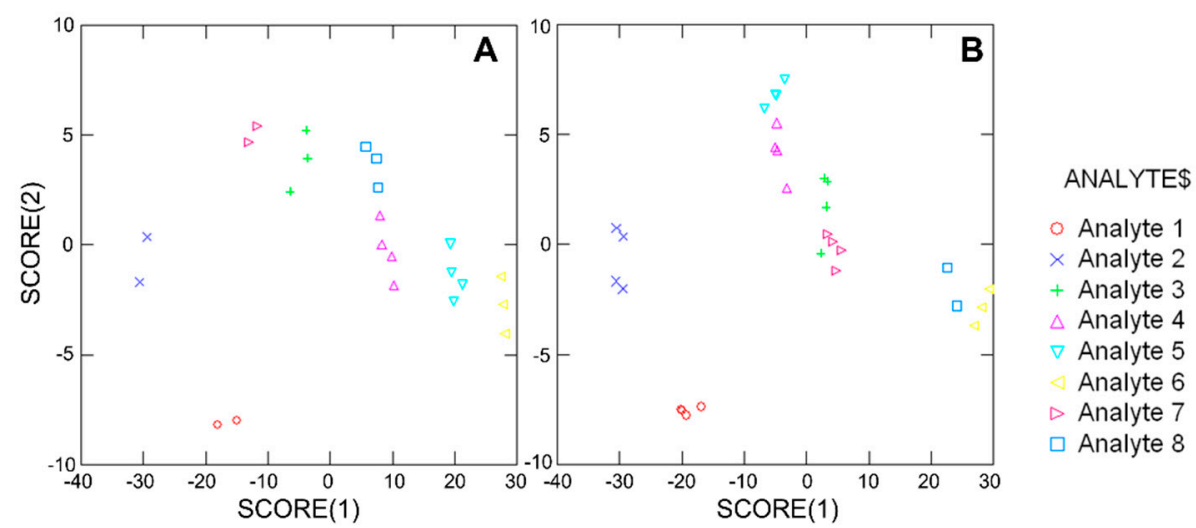

Figure 9. Linear discriminant analysis of fluorescence response patterns of analytes 1-8 with fluorophore 9 in Kingston snow, with (A) $\beta$-cyclodextrin and methyl- $\beta$-cyclodextrin as predictors, as well as (B) $\beta$-cyclodextrin and phosphate-buffered saline as predictors.

Additionally, the differences in sampling location were also detectable using array-based analysis. By comparing the fluorescence response patterns of structural isomers 4-6 in the three snow melt samples and in deionized water (Figure 10), 96\% separation of signals for each isomer in the different complex environments was observed.

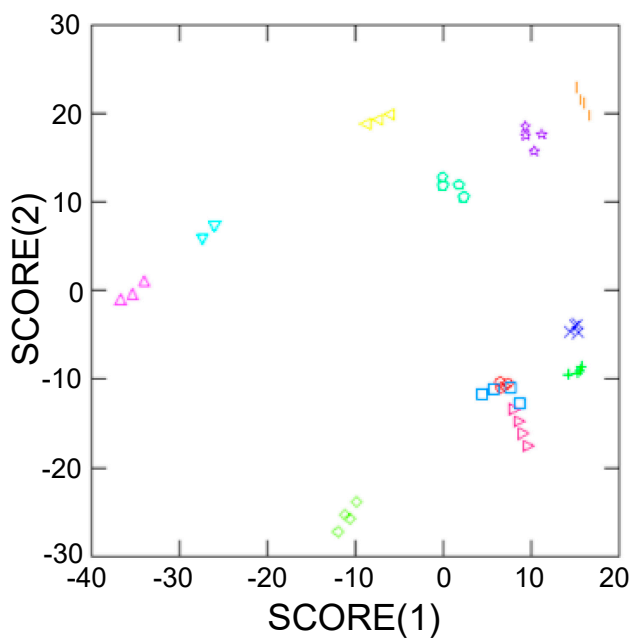

\section{ANALYTES}

DI Water m-xylene

DI Water o-xylene

DI Water p-xylene

Newport m-xylene

Newport o-xylene

Newport p-xylene

Providence m-xylene

Providence o-xylene

Providence p-xylene

Kingston m-xylene

Kingston o-xylene

Kingston p-xylene

Figure 10. Linear discriminant analysis of fluorescence response patterns of analytes 4-6 with fluorophore 9 in Newport snow, Providence snow, Kingston snow, and deionized water, with cyclodextrins as predictors.

In addition to being able to differentiate single components with high levels of accuracy, the ability to accomplish detection of toxicant mixtures in complex environments has significant additional benefits. To that end, linear discriminant analysis was performed on fluorescence responses of mixtures of analytes 4-6 in Kingston snow and in deionized water, and results of these experiments can be seen in Figure 11. Array-based analysis of the response patterns led to $100 \%$ differentiation between the analyte mixtures in both the complex environment of Kingston snowmelt and in the less complex environment of deionized water. Interestingly, the single-component analytes grouped together in both samples, with analyte mixtures appearing on the opposite side of the array. Current efforts in our laboratory are focused on understanding this grouping pattern and on applying our system to additional mixtures of structural isomers in complex environments. 

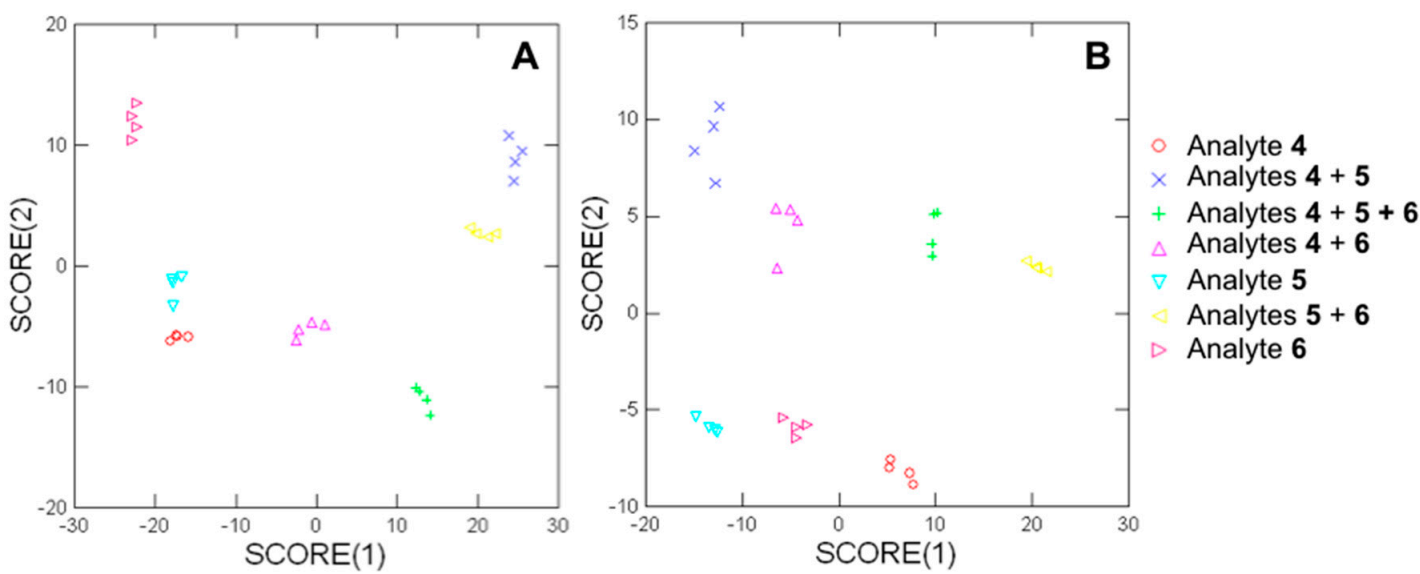

Figure 11. Linear discriminant analysis of mixtures of analytes 4-6 with fluorophore 9 in (A) Kingston snow and (B) deionized water, with cyclodextrins as predictors.

\subsubsection{Limit of Detection Experiments}

In addition to obtaining high selectivity for both single-component analytes as well as analyte mixtures, high sensitivity is also required. The sensitivity of the system was determined by calculating limits of detection for analytes 1-7 in each snow sample, using methyl- $\beta$-cyclodextrin as a supramolecular host (see Tables S8-S10 in the ESI for more details). Methyl- $\beta$-cyclodextrin was chosen as the host for these experiments because it generally led to the highest degree of fluorescence modulation, suggesting strong steric complementarity between the host and guest and concomitant sensitivity to the addition of small amounts of analyte. LODs ranged from $4.02 \mu \mathrm{M}$ to $63.03 \mu \mathrm{M}$. In general, limits of detection were higher than in our previously investigated analytes or matrices, which could be attributed to the general complexity of the snow samples, specifically the fact that significant amounts of other organic components can complicate detection results.

Array-based analysis was also applied to different concentrations of analyte 1, with the goal of developing quantitative array-based detection schemes (Figure 12). Of note, this array led to $100 \%$ differentiation between different concentrations of analyte $\mathbf{1}$ in Providence snow melt, meaning that relatively small differences in the concentration of analyte 1 -in the concentration range of $25 \mu \mathrm{M}$ to $148 \mu \mathrm{M}$-could be differentiated successfully by using array-based analysis. Future work in our laboratory will be focused on differentiating between lower concentrations of analytes at and near the measured detection limits, and on extending these results to detect other analytes quantitatively.

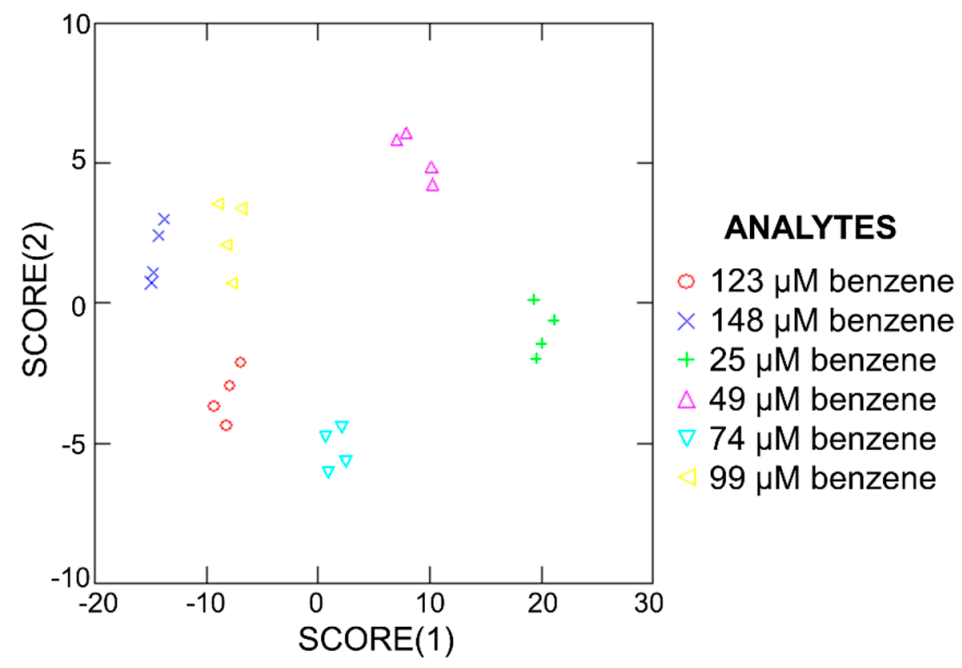

Figure 12. Array-based detection of various concentrations of analyte $\mathbf{1}$ with fluorophore $\mathbf{9}$ in Providence snow, with cyclodextrins as predictors. 


\subsection{Conclusions}

Cyclodextrin-promoted fluorescence modulation was used for the detection of BTEXC compounds in fuel-contaminated snow samples. This method was successful in differentiating between: the sites of snow melt; structurally similar analytes in each of the snow samples, including structural isomers ortho-, meta-, and para-xylene; and in different concentrations of a single target analyte in a complex snow sample. Future work in our laboratory will be focused on expanding the array-based detection technique to quantify more analytes in complex samples, and on improving selectivity in the differentiation of structural isomers to achieve $100 \%$ selectivity.

Supplementary Materials: The following are available online at http:/ /www.mdpi.com/2227-9040/7/1/5/s1, Supplementary information contains summary tables and summary figures for all experiments.

Author Contributions: This manuscript was written through contributions of all authors. D.J.D. designed the experiments. L.E.I., A.H., and S.B.D. performed the experiments. D.J.D. and M.L. analyzed the data; D.J.D. and M.L. wrote the paper. All authors have given approval to the final version of the manuscript.

Funding: Funding is acknowledged from the University of Rhode Island Chemistry Department and the Rhode Island Idea Network of Biomedical Research Excellence (RI-INBRE; grant \# P20GM103430).

Acknowledgments: We would also like to thank Teresa Mako, a graduate student at the University of Rhode Island, for collecting the Providence snow melt sample.

Conflicts of Interest: The authors declare no conflict of interest.

\section{References}

1. Slominska, M.; Konieczka, P.; Namiesnik, J. The fate of BTEX compounds in ambient air. Critical Rev. Environ. Sci. Technol. 2014, 44, 455-472. [CrossRef]

2. De Gennaro, G.; Dambruoso, D.M.; Di Gilio, A.; Marzoca, A.; Tutino, M. Indoor and outdoor volatile organic compounds monitoring in a multi-storey car park. Environ. Engineer. Manag. J. 2015, 14, 1563-1570. [CrossRef]

3. Chambers, D.M.; Reese, C.M.; Thornburg, L.G.; Sanchez, E.; Rafson, J.P.; Blount, B.C.; Ruhl, J.R.E.; De Jesus, V.R. Distinguishing petroleum (crude oil and fuel) from smoke exposure within populations based on the relative blood levels of benzene, toluene, ethylbenzene, and xylenes (BTEX), styrene and 2,5-dimethylfuran by pattern recognition using artificial neural networks. Environ. Sci. Technol. 2018, 52, 308-316. [CrossRef] [PubMed]

4. Sirotkin, A.V.; Harrath, A.H. Influence of oil-related environmental pollutants on female reproduction. Reprod. Toxicol. 2017, 71, 142-145. [CrossRef] [PubMed]

5. Costa, C.; Miozzi, E.; Teodoro, M.; Briguglio, G.; Rapisadra, V.; Fenga, C. New insights on 'old' toxicants in occupational toxicology (Review). Mol. Med. Rep. 2017, 15, 3317-3322. [CrossRef] [PubMed]

6. Mosallanejad, Z.; Fakhri, Y.; Ferrante, M.; Zandsalimi, Y.; Amirhajeloo, L.R.; Amanidaz, N.; Moradi, B.; Keramati, H. Association between benzene exposure and childhood leukemia: A systematic review and meta-analysis updated to July 2016. Int. J. Pharm. Technol. 2016, 8, 4640-4652.

7. Hannigan, J.H.; Bowen, S.E. Reproductive toxicology and teratology of abused toluene. Syst. Biol. Reprod. Med. 2010, 56, 184-200. [CrossRef]

8. Ikemoto, Y.; Motoba, K.; Suzuki, T.; Uchida, M. Quantitative structure-activity relationships of nonspecific and specific toxicants in several organism species. Environ. Toxicol. Chem. 1992, 11, 917-930. [CrossRef]

9. Varona-Torres, E.; Carlton, D.D., Jr.; Hildebrand, Z.L.; Schug, K.A. Matrix-effect-free determination of BTEX in variable soil compositions using room temperature ionic liquid co-solvents in static headspace gas chromatography mass spectrometry. Anal. Chim. Acta. 2018, 1021, 41-50. [CrossRef]

10. Beller, H.R. Analysis of benzylsuccinates in groundwater by liquid chromatography/tandem mass spectrometry and its use for monitoring in situ BTEX biodegradation. Environ. Sci. Technol. 2002, 36, 2724-2728. [CrossRef]

11. Dilonardo, E.; Alvisi, M.; Rossi, R.; Cassano, G.; Di Palo, F.; Palazzo, G.; Penza, M. Sensing properties of MWCNTs layers electrodecorated with metal nanoparticles for detection of aromatic hydrocarbon compounds. MRS Adv. 2017, 2, 1009-1014. [CrossRef] 
12. Colozza, N.; Kehe, K.; Popp, T.; Steinritz, D.; Moscone, D.; Arduini, F. Paper-based electrochemical sensor for on-site detection of the sulphur mustard. Environ. Sci. Poll. Res. 2018. [CrossRef]

13. Al-Madhagi, S.; Joda, H.; Jauset-Rubio, M.; Ortiz, M.; Katakis, I.; O'Sullivan, C.K. Isothermal amplification using modified primers for rapid electrochemical analysis of coeliac disease associated DQB1*02 HLA Allele. Anal. Biochem. 2018, 556, 16-22. [CrossRef] [PubMed]

14. Tu, J.; Gan, Y.; Liang, T.; Wan, H.; Wang, P. A Miniaturized electrochemical system for high sensitive determination of chromium (VI) by screen-printed carbon electrode with gold nanoparticles modification. Sens. Actuators B Chem. 2018, 272, 582-588. [CrossRef]

15. Dutta, M.; Das, D. Recent developments in fluorescent sensors for trace-level determination of toxic-metal ions. Trends Anal. Chem. 2012, 32, 113-132. [CrossRef]

16. Ding, H.; Chen, C.; Qi, S.; Han, C.; Yue, C. Smartphone-based spectrometer with high spectral accuracy for mHealth application. Sens. Actuators A Phys. 2018, 274, 94-100. [CrossRef]

17. Kimura, K.; Onishi, S.; Moriyama, K. Fluorescence-based high-throughput salt screening. J. Pharm. Sci. 2018, 107, 1870-1878. [CrossRef]

18. Thomas, S.W., III; Joly, G.D.; Swager, T.M. Chemical sensors based on amplifying fluorescent conjugated polymers. Chem. Rev. 2007, 107, 1339-1386. [CrossRef]

19. Marks, P.; Cohen, S.; Levine, M. Highly efficient quenching of nanoparticles for the detection of electron-deficient nitroaromatics. J. Polym. Sci. A Polym. Chem. 2013, 51, 4150-4155. [CrossRef]

20. Sokkalingam, P.; Kim, D.S.; Hwang, H.; Sessler, J.L.; Lee, C.-H. A dicationic calix[4]pyrrole derivative and its use for the selective recognition and displacement-based sensing of pyrophosphate. Chem. Sci. 2012, 3, 1819-1824. [CrossRef]

21. Radaram, B.; Mako, T.; Levine, M. Sensitive and selective detection of cesium via fluorescence quenching. Dalton Trans. 2013, 42, 16276-16278. [CrossRef] [PubMed]

22. Saar-Reismaa, P.; Erme, E.; Vaher, M.; Kulp, M.; Kaljurand, M.; Mazina-Sinkar, J. In situ determination of illegal drugs in oral fluid by portable capillary electrophoresis with deep UV excited fluorescence detection. Anal. Chem. 2018, 90, 6253-6258. [CrossRef] [PubMed]

23. Campos-Candel, A.; Llobat-Estelles, M.; Mauri-Aucejo, A. Comparative evaluation of liquid chromatography versus gas chromatography using a beta-cyclodextrin stationary phase for determination of BTEX in occupational environments. Talanta 2009, 78, 1286-1292. [CrossRef] [PubMed]

24. Serio, N.; Moyano, D.F.; Rotello, V.M.; Levine, M. Array-based detection of persistent organic pollutants via cyclodextrin-promoted energy transfer. Chem. Commun. 2015, 51, 11615-11618. [CrossRef] [PubMed]

25. DiScenza, D.J.; Levine, M. Selective detection of non-aromatic pesticides via cyclodextrin-promoted fluorescence modulation. New J. Chem. 2016, 40, 789-793. [CrossRef]

26. Serio, N.; Chanthalyma, C.; Prignano, L.; Levine, M. Cyclodextrin-promoted energy transfer for broadly applicable small-molecule detection. Supramol. Chem. 2014, 26, 714-721. [CrossRef]

27. DiScenza, D.J.; Gareau, L.; Serio, N.; Roque, J.; Prignano, L.; Verderame, M.; Levine, M. Cyclodextrin-promoted detection of aromatic toxicants and toxicant metabolites in urine. Anal. Chem. Lett. 2016, 6, 345-355. [CrossRef]

28. DiScenza, D.J.; Lynch, J.; Verderame, M.; Serio, N.; Prignano, L.; Gareau, L.; Levine, M. Efficient fluorescence detection of aromatic toxicants and toxicant metabolites in human breast milk. Supramol. Chem. 2018, 30, 267-277. [CrossRef]

29. Serio, N.; Levine, M. Efficient extraction and detection of aromatic toxicants from crude oil and tar balls using multiple cyclodextrin derivatives. Marine Pollut. Bull. 2015, 95, 242-247. [CrossRef]

30. DiScenza, D.J.; Lynch, J.; Miller, J.; Verderame, M.; Levine, M. Detection of organochlorine pesticides in contaminated marine environments via cyclodextrin-promoted fluorescence modulation. ACS Omega 2017, 2, 8591-8599. [CrossRef]

31. DiScenza, D.J.; Levine, M. Detection of benzene and alkylated benzene derivatives in fuel-contaminated environments. CLEAN Soil Air Water 2016, 44, 1621-1627. [CrossRef]

32. Xue, B.-X.; Wei, L.; Li, C.-Y.; Li, T.-Y. A study of the distribution and composition of pollutants in snow collected from streets and a treatment system for recycling snow in winter cities. Desalin. Water Treat. 2015, 54, 1470-1478. [CrossRef] 
33. Hers, I.; Jourabchi, P.; Lahvis, M.A.; Dahlem, P.; Luo, E.H.; Devaull, G.E.; Mayer, K.U. Evaluation of seasonal factors on petroleum hydrocarbon vapor biodegradation and intrusion potential in a cold climate. Groundwater Monit. Remediat. 2014, 34, 60-78. [CrossRef]

34. Nazarenko, Y.; Fournier, S.; Kurien, U.; Rangel-Alvarado, R.B.; Nepotchatykh, O.; Seers, P.; Ariya, P.A. Role of snow in the fate of gaseous and particulate exhaust pollutants from gasoline-powered vehicles. Environ. Pollut. 2017, 223, 665-675. [CrossRef]

35. Martel, C.J.; Nadeau, B.M.J. Snow as an expedient sorbent for hazardous materials. Environ. Sci. Health A 1994, A29, 237-247. [CrossRef]

36. Cheng, D.; Zhao, W.; Yang, H.; Huang, Z.; Liu, X.; Han, A. Detection of $\mathrm{Hg}^{2+}$ by a FRET ratiometric fluorescent probe based on a novel BODIPY-RhB system. Tetrahedron Lett. 2016, 57, 2655-2659. [CrossRef]

37. Wenning, R.J.; Harris, M.A.; Ungs, M.J.; Paustenbach, D.J.; Bedbury, H. Chemometric comparisons of polychlorinated dibenzo-p-dioxin and dibenzofuran residues in surficial sediments from Newark Bay, New Jersey and other industrialized waterways. Arch. Environ. Contam. Toxicol. 1992, 22, 397-413. [CrossRef]

38. Acid Rain Has Negative Impact on Rhode Island's Lake Fish. Available online: http:/ / turnto10.com/news / videos / acid-rains-impact-on-rhode-island-lakes (accessed on 25 June 2018).

39. Loftsson, T.; Jarho, P.; Masson, M.; Jarvinen, T. Cyclodextrins in drug delivery. Expert Opin. Drug Deliv. 2005, 2, 335-351. [CrossRef]

40. Li, B.; Chen, J.B.; Xiong, Y.; Zhao, C.; Sun, J. Development of turn-on fluorescent probes for the detection of $\mathrm{H}_{2} \mathrm{O}_{2}$ vapor with high selectivity and sensitivity. Sens. Actuators B Chem. 2018, 268, 475-484. [CrossRef]

41. Zhang, M.; Su, R.; Zhang, Q.; Hu, L.; Tian, X.; Chen, Y.; Zhou, H.; Wu, J.; Tian, Y. Ultra-bright intercellular lipids pseudo Di-BODIPY probe with low molecular weight, high quantum yield and large two-photon action cross-sections. Sens. Actuators B Chem. 2018, 261, 161-168. [CrossRef]

42. Richards, G.J.; Gobo, Y.; Yamamura, M.; Nabeshima, T. Biphenyl appended BODIPY derivatives showing combined environmental polarity and heavy metal cation sensing functionality. New J. Chem. 2015, 39, 5886-5889. [CrossRef]

43. Sarti, E.; Pasti, L.; Scaroni, I.; Casali, P.; Cavazzini, A.; Rossi, M. Determination of n-alkanes, PAHs, and nitro-PAHs in PM2.5 and PM1 sampled in the surroundings of a municipal waste incinerator. Atmos. Environ. 2017, 149, 12-23. [CrossRef]

44. Cho, H.S.; Das, M.; Wang, H.; Dinh, H.N. The contamination mechanism and behaviour of amide bond containing organic contaminant PEMFC. J. Electrochem. Soc. 2015, 162, F427-F435. [CrossRef]

45. Zare, A.; Nabi, M.N.; Bodisco, T.A.; Hossain, F.M.; Rahman, M.M.; Ristovski, Z.D.; Brown, R.J. The effect of triacetin as a fuel additive to waste cooking biodiesel on engine performance and exhaust emissions. Fuel 2016, 182, 640-649. [CrossRef]

46. Dong, T.; Fei, Q.; Genelot, M.; Smith, H.; Laurens, L.M.L.; Watson, M.J.; Pienkos, P.T. A novel integrated biorefinery process for diesel fuel blendstock production using lipids from the methanotroph, methylmicrobium buryatense. Energy Convers. Manag. 2017, 140, 62-70. [CrossRef]

47. Brewer, R.; Nagashima, J.; Kelley, M.; Heskett, M.; Rigby, M. Risk-based evaluation of total petroleum hydrocarbons in vapor intrusion studies. Int. J. Environ. Res. Public Health 2013, 10, 2441-2467. [CrossRef] [PubMed]

48. Bosker, T.; Santoro, G.; Melvin, S.D. Salinity and sensitivity to endocrine disrupting chemicals: A comparison of reproductive endpoints in small-bodied fish exposed under different salinities. Chemosphere 2017, 183, 186-196. [CrossRef]

49. Cai, W.; Sun, T.; Shao, X.; Chipol, C. Can the anomalous aqueous solubility of $\beta$-cyclodextrin be explained by its hydration free energy alone? Phys. Chem. Chem. Phys. 2008, 10, 3236-3243. [CrossRef]

50. Nojavan, S.; Yazdanpanah, M. Micro-solid phase extraction of benzene, toluene, ethylbenzene and xylenes from aqueous solutions using water-insoluble $\beta$-cyclodextrin polymer as sorbent. J. Chromatogr. A. 2017, 1525, 51-59. [CrossRef]

51. Nowicki, A.; Zhang, Y.; Leger, B.; Rolland, J.P.; Bricout, H.; Monifer, E.; Roucoux, A. Supramolecular shuttle and protective agent: A multiple role of methylated cyclodextrins in the chemoselective hydrogenation of benzene derivatives with ruthenium nanoparticles. Chem. Commun. 2006, 296-298. [CrossRef] 
52. Misawa, K.; Saito, Y.; Hashizaki, K.; Taguchi, H.; Ogawa, N.; Ueda, H. Stability constants for 1:1 complexes formed between 2-hydroxypropyl- $\beta$-cyclodextrin with an average substitution degree of 4.4 and benzene and alkylbenzenes as guests by modified static head-space gas chromatography method. J. Incl. Phenom. Macrocycl. Chem. 2005, 53, 237-240. [CrossRef]

53. Gomez, E.C.; Anguiano Igea, S.; Gomez Amoza, J.L.; Ottero Espinar, F.J. Evaluation of the promoting effect of soluble cyclodextrins in drug nail penetration. Eur. J. Pharm. Sci. 2018, 117, 270-278. [CrossRef]

54. Sen, C.P.; Shrestha, R.G.; Shrestha, L.K.; Ariga, K.; Valiyaveetil, S. Low-band-gap BODIPY conjugated copolymers for sensing volatile organic compounds. Chem. Eur. J. 2015, 21, 17344-17354. [CrossRef]

55. Qiu, J.; Jiang, S.; Guo, H.; Yang, F. An AIE and FRET-based BODIPY sensor with large stokes shift: Novel $\mathrm{pH}$ probe exhibiting application in $\mathrm{CO}_{3}{ }^{2-}$ detection and living cell imaging. Dyes Pigm. 2018, 157, 351-358. [CrossRef]

56. Ziessel, R.; Ulrich, G.; Harriman, A. The chemistry of bodipy: A new El Dorado for fluorescence tools. New J. Chem. 2007, 31, 496-501. [CrossRef]

57. DiScenza, D.J.; Culton, E.; Verderame, M.; Lynch, J.; Serio, N.; Levine, M. Towards rational chemosensor design through improved understanding of experimental parameter variation and tolerance in cyclodextrin-promoted fluorescence detection. Chemosensors 2017, 5, 34. [CrossRef]

58. Kfoury, M.; Landy, D.; Fourmentin, S. Characterization of cyclodextrin/volatile inclusion complexes: A review. Molecules 2018, 23, 1204. [CrossRef]

59. Saha, S.; Agarwalla, H.; Gupta, M.; Suresh, S.K.; Ghosh, S.K.; Das, A. New chemodosimetric probe for the specific detection of $\mathrm{Hg}^{2+}$ in physiological condition and its utilisation for cell imagine studies. Dalton Trans. 2013, 42, 15097-15105. [CrossRef]

60. DiScenza, D.J.; Lynch, J.; Feder, E.; Levine, M. Detection of bisphenol A and derivatives in human urine via cyclodextrin-promoted fluorescence modulation. Anal. Methods 2018, 10, 3783-3790. [CrossRef]

61. Castronuovo, G.; Niccoli, M. Solvent effects on the complexation of 1-alkanols by parent and modified cyclodextrins. Calorimetric studies at 298 K. J. Thermal Anal. Calorim. 2011, 103, 641-646. [CrossRef]

(C) 2019 by the authors. Licensee MDPI, Basel, Switzerland. This article is an open access article distributed under the terms and conditions of the Creative Commons Attribution (CC BY) license (http:/ / creativecommons.org/licenses/by/4.0/). 